\title{
Relationships among transformational leadership, organizational climate, organizational citizenship behavior and performance in Romanian employees
}

\author{
Wasim Get ${ }^{1}$ \\ ${ }^{1}$ Department of Psychology, University of Bucharest, Romania.
}

Received 11.07.2018; Received revised 7.12.2018; Accepted 20.12.2018

Available online 31.12.2018

\begin{abstract}
In this paper we identified on the one hand the relationship among transformational leadership, organizational climate, organizational citizenship behavior, and performance, and on the other hand the mediating role of organizational citizenship behavior in the relation between transformational leadership and the performance of Romanian employees. The participants were 316 employees from small, medium and large Romanian companies. The male and female participants were selected from private sector economic organizations, either manufacturing companies or service providers. The results showed that transformational leadership was positively associated with the organizational climate, organizational citizenship behavior, and employees' performance. The organizational citizenship behavior was positively associated with employees' performance. It was also noticed that organizational citizenship behavior mediates the relationship between leadership and performance, with relatively equal effects on task performance and on contextual performance. By understanding the importance of leadership style in the organizational environment, leadership skills improvement programs may be developed to enhance the performance of the organization.
\end{abstract}

Keywords: transformational leadership, organizational climate, organizational citizenship behavior, performance.

Address of correspondence: Wasim Get, Department of Psychology, University of Bucharest, Bd. M. Kogălniceanu 36-46, Sector 5, 050107, Bucharest, Romania.

E-mail: wasim.get@isracenter.com

\section{Introduction}

Transformational leadership, healthy organizational climate, and employee performance are common concepts in the sphere of organizational psychology. Learning the relationships among these variables may have a significant contribution to the proper functioning of organizations in Romania. Although the literature abounds in studies on these issues, there is not enough empirical research in Romania to portray these relationships as they really are. We believe that such a study brings additional value by using data collected from companies currently operating in Romania, as well as data on Romanian leaders and employees, in the current economic and political context.

This study aims to achieve two objectives of great interest for organizational psychology in Romania. The first objective is to identify the associations of transformational leadership with the development of a healthy organizational climate. The second objective is to establish the mediating role of the organizational citizenship behavior in the relationship between transformational leadership and employees' performance.

The purpose of the study is to provide an insight into the organizational environment of some of the companies currently operating in Romania and to analyze employees' perceptions about the transformational leadership style, but also the relationships that are established between this leadership style and other components of organizational environment such as organizational climate, organizational citizenship behavior and employee performance.

Transformational leadership and organizational climate

The theory of transformational leadership still occupies a central position in the field of organizational psychology. This theory was developed by Burns (1978) and was later improved by Bass $(1985,1998)$ and by other specialists (Avolio and Bass, 1988; Bennis and Nanus 1985; Tichy and Devanna 1986). The basic idea of the transformational leadership theory lies in the leader's ability to motivate 
employees to achieve results beyond their personal expectations (Krishnan, 2005).

Vera and Crossan (2004) emphasize that transformational leadership helps subordinates to unravel their old routines, develop creative solutions to confront ambiguous issues, and adapt appropriately to new environments. Burns (1978) was the first author to highlight the differences between transactional leadership and transformational leadership. Transactional leadership involves the existence of exchange based relationships between the leader and the members of his team. Such exchanges may use salary or prestige as leverage to meet the requirements of the leader, thus focusing on the reward for the effort and compliance or conformism. Transformational leadership, on the other hand, aims to transform individuals, motivates them to achieve performance by changing their attitudes, beliefs and values. Bass (1985) identified a number of sub-dimensions of the transformational leadership style, such as charisma, inspirational motivation, intellectual stimulation, individualized consideration.

Transformational leaders provide employees with a solid view of their opportunities, encourage their critical thinking about initiating changes, contribute to increasing confidence in their own adaptability, and emphasize the importance of their performance by linking their own interests with organizational interests (Bass, 1999). Starting with this type of influence, employees tend to react positively to change, both attitudinal and behavioral. In this respect, Herold, Fedor, Caldwell, \& Liu (2008) noticed some positive associations between transformational leadership and employee involvement in new situations. At the same time, Detert and Burris (2007) demonstrated that transformational leadership is a consistent predictor of work performance.

At a strategic level, there are numerous attempts to change and the communication involved in these attempts is formal, encrypted and directed to a large number of people. On the other hand, at lower hierarchical levels, changes are gradually implemented in lower volumes, involve an informal manner of communication and active participation of employees (Rafferty and Restubog, 2010). Managers who implement change have more chances to shape this change and engage in genuine conversations with employees, face to face and unscheduled meetings. On the other hand, the questions and problems posed by employees can stimulate a considerable part of the communication on change. Direct engagement involves more employees at the same time, and misunderstandings about change can be solved by bottom-up inputs about the work process. Through such interpersonal interactions, employees develop positive reactions and become motivated to start changing the situation (Levay, 2010). The transformational leader dedicates more time to coaching and guidance, so as to increase the quality of employee relationships (Liu and Batt, 2010), which will lead to reciprocity of responsibility, trust, respect and interpersonal support (Sun, Aryee, \& Law, 2007). Employees who engage in quality relationships with their managers will have higher performances and will demonstrate more organizational civic behavior (Cropanzano and Mitchell, 2005).

Transformational leaders transmit a strong vision of growth opportunities within their organization and work team, they motivate employees to think critically and constructively about the changes that occur at the organization level and cause them to align their personal goals with those of the company in which they work (Bass and Avolio, 1994; Gardner and Avolio, 1998). These leaders call for employees' ideals and values, which facilitates their involvement in the organization's activities (Piccolo and Colquitt, 2006), while providing meaning to their work by promoting high values, and thus helping employees to reconcile their personal values and those of the organization (Bono and Judge, 2003). As employees are more connected to the goals of the organization, the possibility of experiencing negative emotions that could generate stressful, unreliable and excessively flexible work contexts diminishes (Moss et al., 2009).

At group level, transformational leadership imparts a pattern of behaviors that propagate over the entire context of work (Cho and Dansereau, 2010). Through social learning, employees interact with the leader and develop a common perception of their behavior, generating a transformative work environment (Zohar and Tenne-Gazit, 2008). This organizational climate reflects the rules (spoken) within the company.

The organizational climate is defined as a set of common perceptions about policies, practices and procedures that carry the intra-organizational messages about what is rewarded, what is allowed and what is valued in the organization, being generated by social interactions that occur at group level (Kuenzi and Schminke, 2009). As a collective phenomenon, the organizational climate coordinates employee behaviors by helping them in giving meaning to work situations and orienting them towards the objectives (Schneider and Reichers, 1983).

The organizational climate is a basic component of the organizational environment in general and it represents the right context for studying organizational behaviors at a global, group or individual level. Although the organizational climate is a long-standing construct, there is no unanimous opinion amongst the specialists about the dimensions it encompasses (Patterson et al., 2004). The organizational climate refers to the specific aspects of the work environment that employees perceive consciously, to the formal and informal work atmosphere, to what employees see and feel about their work environment. Despite having a purely subjective nature at individual level, the perception of the organizational climate at group level becomes a summary of the image that employees shape about their work context. Thus, it is the global expression of what the organization really is (Evans, Hodkinson, Rainbird, \& Unwin, 2006). According to Calahane and Sites (2008), the organizational climate represents the collective perception of the working environment, as it is received by the members of a system. The authors add that the organizational climate is a stable structure which stands the test of time and gets a lot of inertia over the generations of employees coming and going.

According to Ekvall and Tangeberg-Andresson (1986), among the factors that determine the organizational climate, leadership occupies the main place, being the most influential element. Changing leadership leads directly to climate change. The close link between leadership and the organizational climate has been studied and mentioned by many specialists, and literature shows numerous studies attesting to this association (Gil et al., 2005).

Koene et al. (2002), in a study with over 2000 employees from 50 supermarkets, noted that leadership style is a consistent predictor for both the organizational climate and the financial performance of the supermarkets which were included in the study. As stated by Mumford et 
al. (2002), organizational climate and culture are collective social constructs over which leaders exercise substantial control and influence.

A meta-analysis conducted by Wang et al. (2011) pointed out among other things that transformational leadership has significant effects on the organizational climate. Positive leadership types are more strongly associated with less demoralizing organizational climate (Schneider et al., 2013). Stringer (2002) addresses the leadership-climate relationship by using an analogy with the cause-effect relationship. What the head of a working group does is the most important determinant of the climate. The behavior of the leader determines the climate, which stimulates motivation. And increased motivation is an impetus for global performance. Thus, daily management practices - in Stringer's opinion - are the most important determinant of the climate for the following three reasons: 1) leadership impregnates an organization; other climate determinants, such as organizational arrangements and strategy, are communicated to the members of the organization through the words and the actions of the manager; 2) organizational research conducted so far has shown that the leadership factor has the greatest impact on the climate; 3) leadership is the determinant of the climate that is the easiest to change, or at least to be influenced, so climate change and performance are obtained faster by changing leadership practices.

H1. Transformational leadership is positively associated with organizational climate.

Transformational leadership, organizational citizenship behavior, and performance

An essential component of the organizational environment, which contributes to growth and performance, is organizational citizenship behavior. This construct refers to the actions that employees choose to carry out spontaneously, on their own initiative and not as part of their specific work tasks. Organizational citizenship behavior cannot be recognized and rewarded directly at the organizational level, but can facilitate indirect rewards and make a significant contribution to the organization's wellfunctioning (Organ, 1988).

Organizational citizenship behavior reflects the flexible nature of work roles and is manifested by helping colleagues, assisting newcomers, working overtime, shifting with others when needed, and numerous voluntary actions that contribute to the organization's good work, in the absence of expectations regarding additional remuneration (Van Scotter, Motowidlo, \& Cross, 2000).

By adopting organizational citizenship behaviors, beneficial effects are achieved in three areas. First of all, employees are more appreciated by their managers (Podsakoff et al., 2009) due to the fact that the latter deem that this behavior plays an important role in the success of the organization and the cohesion of the work teams (Organ et al., 2006). Secondly, the appreciation received from managers is associated with receiving rewards (Podsakoff et al., 2009), such as salary increases, bonuses, promotions, or other work-related benefits. Thirdly, employees with a high organizational citizenship behavior have greater chances of being retained in organizations in crisis or restructuring situations.

Organ et al. (2006) argue that the effects of this behavior are beneficial at both individual and organizational levels, contributing to the increased productivity, availability of resources, attracting and retaining good employees, building and strengthening social capital.

Social exchange theory is often used to check the level of reciprocity manifested by employees in work activities. Social exchanges take the form of "goodwill" gestures and take place between employees and the organization or between subordinates and managers when their reciprocity is guaranteed. Both social exchanges and reciprocity highlight the fact that individuals are interconnected through mutual dependence, and this dependence is characteristic of the employee-organization relationship.

Organizational citizenship behavior involves two complementary aspects. The first aspect includes those behaviors that have a direct impact on the balance of social exchanges between employees and the organization (OCBO). The second aspect includes behavior with indirect impact on individuals (OCBI). Lee and Allen (2002) argue that as long as organizational citizenship behavior is a deliberate attempt to maintain the balance of social exchanges between employees and the organization, it is more geared towards bringing benefits to the organization.

Studies have shown that there is a strong link between organizational citizenship behavior and the transformational leadership style (Asgari et al., 2008; Boerner, Eisenbeiss, \& Griesser, 2007; Oguz, 2010). Also, organizational civic behavior is positively associated with individual, group or organization performance (Luthans, 2011; Chiang and Tsung, 2012).

Another component of the organizational environment that is the subject of this study is work performance, perhaps the variable with the highest level of dependence in organizational psychology. Borman and Motowidlo (1993) identified two major classes of employee behavior: task performance and contextual performance. Task performance involves behavioral patterns directly linked to manufacturing goods, service providing, or activities related to organizations' specific technical processes. It uses quantitative and qualitative criteria to evaluate the results. Contextual performance is an individual effort that is not directed to the production of products or services but to the modeling of the organizational, social and psychological context, which plays the role of a powerful catalyst for fulfilling the tasks (Werner, 2000).

The relationships of transformational leadership, organizational citizenship behavior and work performance are vast and complex. Studies in this field have shown the most diverse results. Leadership is considered a factor of major influence on performance in all its aspects, at organization level, at managerial level or at individual level (Wang et al., 2005).

Organizational citizenship behavior in itself is a positive behavioral phenomenon that produces beneficial effects on performance in all its aspects (Podsakoff, MacKenzie, Paine, \& Bachrach, 2000) and benefits both organizations and their members (Ackfeldt and Leonard, 2005). Previous studies have shown that transformational leadership has direct effects on organizational citizenship behavior (MacKenzie, Podsakoff, \& Rich, 2001), determining the leaders to stimulate employees to engage in goodwill towards others and in work activities that go beyond the established goals.

Bass (1990) argued that transformational leaders create employees who are not selfish, are trustworthy, and connected with the organization. Studies have shown that there is a positive association between transformational leadership and citizenship behaviors: helpful, team spirit, 
altruism (MacKenzie et al., 2001; Schlechter and Engelbrecht, 2006).

H2. Transformational leadership is positively associated with organizational citizenship behavior.

Bass (1985) argued that transformational leadership encourages employees to think critically and seek new approaches to work, it motivates them to become more involved, resulting in increased job satisfaction and attachment to the organization with effects on performance.

The relationship between transformational leadership and performance is one of the most studied topics in the literature (Hiller, DeChurch, Murase, \& Doty, 2011). Wang, Oh, Courtright, \& Colbert (2011) conducted a metaanalysis on the effects of leadership on performance, including 113 studies. The results showed that transformational leadership is positively associated with performance and it is linked with contextual performance to a greater extent than with task performance.

Dvir, Eden, Avolio, \& Shamir (2002) conducted an experiment involving 54 military leaders and 814 subordinates. Leaders in the experimental group received a transformational training, and those in the control group received standard training. The results of the subordinates were analyzed and indicated that the individuals led by transformational leaders achieved higher performances than those under the guidance of the leaders having received standard training.

H3. Transformational leadership is positively associated with employee performance.

H3a. Transformational leadership is positively associated with employee task performance.

$H 3 b$. Transformational leadership is positively associated with employee contextual performance.

Organizational citizenship behavior was analyzed by specialists also as a mediator in the relationship between transformational leadership and employee performance (Khokhar and Zia-ur-Rehman, 2017; Ekowati, Troena, \& Noermijati, 2013) and organizational performance (Andrew, Rebecca, \& Shawn, 2011), and employee creativity (Eisenbeis and Boerner, 2013). Transformational leadership emphasizes the importance of social exchanges between leadership and employees in the form of a psychological contract, thus stimulating organizational citizenship behavior. Moreover, organizational citizenship behavior includes extra-role behaviors that are extremely important for the efficiency of organizations (Avolio and Yammarino, 1990). Also, Podsakoff et al. (2000) noted that organizational citizenship behavior predicts employee performance.

Peer helping behaviors lead to improved performance and to the fact that new colleagues are more easily integrated into groups, so groups can build up their best practices, facilitating communication and activity coordination.

Boerner, Eisenbeiss, \& Griesser (2007) conducted a study on the factors that mediate the relationship between transformational leadership and employee performance. The authors hypothesized that transformational leadership increases the performance of employees by stimulating organizational citizenship behavior, based on contradictory debates and discussions that stimulate the creativity of employees. The study was attended by 91 leaders from 91 German companies, and the authors' hypothesis was supported by the data.

H4. Organizational citizenship behavior is positively associated with performance.
H4a. Organizational citizenship behavior is positively associated with task performance.

H4b. Organizational citizenship behavior is positively associated with contextual performance.

H5. Organizational citizenship behavior mediates the relationship between transformational leadership and employee performance.

\section{Method}

\section{Participants}

The sample consists of 316 employees in management and executive positions from small, medium and large Romanian companies. The male and female participants were selected from private economic organizations in a wide range of industries (Table 1). The inclusion criterion in the research group was seniority, i.e. at least six months, and it was based on the assumption that an employee having worked with the company for less than 6 months cannot provide a pertinent opinion on the leadership style and the type of organizational climate.

\section{Measures}

1. Transformational leadership (Rafferty and Griffin, 2004). The scale was developed in 2004 and contains 15 items, three for each of the five subscales: vision, inspirational communication, intellectual stimulation, supportive leadership and personal recognition. Each item was rated on a 5-point Likert scale, where 1 - to a very small extent and 5 - to a very large extent. Item example: "Makes me think in new ways about old issues."

Taking into account that there is a strong correlation among the five dimensions of transformational leadership, only the overall score of this scale was used. The reliability score Cronbach Alpha was $\alpha=.95$.

2. CLIOR, Organizational Climate Scale (Pena-Suarez et al., 2013). The instrument was created according to the principles established by Jones and James (1979), James et al. (2008), Corral \& Perena (2010), allowing the measurement of the organizational climate as a general factor underlying a series of facets. These facets are grouped into three dimensions by Carr, Schmidt, Ford, \& DeShon (2003) and by Ostroff (1993). The first facet, the affective component, includes the attachment to the post as well as the cooperation and relations with colleagues and managers; the second facet, the cognitive component, includes innovation, autonomy and participation; the third facet, the instrumental component, includes the organization, the reward system, the physical conditions and the program. The novelty of this scale consists in the reward component, which was not measured in the previous questionnaires.

The development of the scale was based on a very large item bank that included the dimensions proposed over time by various authors and involved a large number of participants (3163), which contributed to guaranteeing the validity and robustness of the instrument's psychometric properties. Another advantage of the scale is its unidimensionality and the possibility of computerized adaptation, which, in the opinion of the authors, is an important step forward in the organizational climate assessment (Bartram and Hambleton, 2006; Downing and Haladyna, 2006).

The CLIOR Scale was translated and sent for retroversion to two specialists, an authorized translator and a psychologist. After making the necessary corrections, it 
was introduced in the final form. Each item was rated on a 5 -step Likert scale, where 1 - total disagreement and 5 total agreement. Example item: "My job is pleasing". A high score indicates the presence of a healthy, pleasant and satisfactory organizational climate in all aspects: affective, relational and cognitive, while a low score signifies the existence of a disagreeable organizational climate. Although there is also a 15-item version, in the present study we used the version with 50 items. The reliability score Cronbach Alpha was $\alpha=.95$.

3. Lee and Allen's Organizational Citizenship Behaviour Scale. The scale was developed in 2002 and comprises 16 items, eight for each of the two subscales: interpersonal OCB and organizational OCB respectively. Each item was rated on a 7-step Likert scale where 1 Never and 7 - Always. Examples of items: "I help my absent colleagues" or "I express my loyalty to the organization". In this study the global scale score was used. The reliability score Cronbach Alpha was $\alpha=.94$.

4. Goodman \& Svyantek's Performance Scale (Goodman and Svyantek, 1999). The scale comprises 16 items grouped into two subscales, nine for task performance and seven for contextual performance. Each item was rated on a 4-step Likert scale where 1 - strong disagreement and 5 - strong agreement. Example item for task performance: "I meet all the requirements required by my work". Example item for contextual performance: "I help others when they have a lot of work". The reliability score Cronbach Alpha was $\alpha=.91$ for the entire scale, $\alpha=$ .89 for task performance, and $\alpha=.91$ for contextual performance.

\section{Demographics}

The study collected relevant demographic information: gender, age, position, seniority, and type of company (the number of employees).

\section{Procedure}

The study was conducted in Romania and data were collected exclusively online on a volunteer basis, from employees working in 18 Romanian organizations. We firstly contacted the managers of the companies and asked them to distribute the questionnaire to their employees. The participants were approached via email by their supervisors. Of the initial 350 calls (email addresses), only 320 participants volunteered to participate in the study, with 316 participants remaining, whose answers met the conditions of completeness.

\section{Results}

Means, standard deviations, and internal consistencies for all study variables are presented in Table 2 .

$\underline{\text { Table } 2 \text {. Descriptive statistics and reliability coefficients }}$

\begin{tabular}{llll}
\multicolumn{4}{c}{ Descriptors } \\
\hline & $M$ & $S D$ & $\alpha$ \\
1. Transformational leadership & 51.83 & 13.44 & .95 \\
2. Organizational climate & 179.14 & 30.94 & .95 \\
3. OCB & 81.72 & 17.05 & .94 \\
4. Task performance & 30.09 & 3.95 & .89 \\
5. Contextual performance & 22.26 & 3.70 & .91 \\
\hline
\end{tabular}

Note: $\alpha$ indicates the reliability scores.

H1: Correlation analysis was used and the results indicated that transformational leadership was positively associated with organizational climate and the association was statistically significant: $\mathrm{r}=.73, \mathrm{p}<.01$, with an effect size $\mathrm{r}^{2}=.53$.

H2: Correlation analysis was used to test if transformational leadership significantly correlated with organizational citizenship behavior (OCB). The results of the correlation analysis indicated that transformational leadership was positively associated with organizational citizenship behavior and the results were statistically significant: $\mathrm{r}=.42, \mathrm{p}<.01$, with an effect size $\mathrm{r}^{2}=.18$.

Table 1. Demographics of the sample $(\mathrm{N}=316)$

\begin{tabular}{|c|c|c|c|c|c|c|}
\hline Gender & $\begin{array}{l}\text { Men } \\
112 \\
\end{array}$ & $\begin{array}{l}\text { Women } \\
204\end{array}$ & & & & \\
\hline Age (years) & $\begin{array}{l}18-24 \\
68 \\
\end{array}$ & $\begin{array}{l}25-30 \\
87 \\
\end{array}$ & $\begin{array}{l}31-40 \\
84 \\
\end{array}$ & $\begin{array}{l}\text { over } 41 \\
77\end{array}$ & & \\
\hline Position & $\begin{array}{l}\text { Management } \\
60\end{array}$ & $\begin{array}{l}\text { Execution } \\
256\end{array}$ & & & & \\
\hline Seniority & $\begin{array}{l}\text { Beginner, } \\
<2 \text { years } \\
116\end{array}$ & $\begin{array}{l}\text { Intermediate, } \\
3-5 \text { years } \\
70\end{array}$ & $\begin{array}{l}\text { Experimented, } \\
6-8 \text { years } \\
36\end{array}$ & $\begin{array}{l}\text { Senior, } \\
>9 \text { years } \\
94\end{array}$ & & \\
\hline $\begin{array}{l}\text { No of org. } \\
\text { employees }\end{array}$ & $\begin{array}{l}1-9 \\
63\end{array}$ & $\begin{array}{l}10-49 \\
84\end{array}$ & $\begin{array}{l}50-249 \\
88\end{array}$ & $\begin{array}{l}250-499 \\
17\end{array}$ & $\begin{array}{l}500-999 \\
14\end{array}$ & $\begin{array}{l}>1000 \\
50\end{array}$ \\
\hline
\end{tabular}

Table 3. Pearson correlation for Transformational Leadership and Performance

\begin{tabular}{llll} 
& & & \\
& Transformational leadership & Task performance & $\begin{array}{l}\text { Contextual } \\
\text { performance }\end{array}$ \\
\hline Transformational leadership & 1 & & \\
Task performance & $.27^{* *}$ & 1 & 1 \\
Contextual performance & $.38^{* *}$ & $.70^{* *}$ & 1 \\
\hline$* * . p<.01$. & &
\end{tabular}

**. $\mathrm{p}<.01$. 
Table 4. Pearson correlation for Organizational citizenship behavior and Performance

\begin{tabular}{llll}
\hline & OCB & Task performance & $\begin{array}{l}\text { Contextual } \\
\text { performance }\end{array}$ \\
\hline OCB & 1 & & \\
Task performance & $.53^{* *}$ & 1 & \\
Contextual performance & $.72^{* *}$ & $.70^{* *}$ & 1 \\
\hline$* * . p<.01$. & & &
\end{tabular}

**. $\mathrm{p}<.01$.

Table 5. Mediation Estimates for Transformational Leadership on Task Performance through OCB

\begin{tabular}{|c|c|c|c|c|c|c|c|c|}
\hline \multirow[b]{2}{*}{ Effect } & \multicolumn{8}{|c|}{ 95\% Confidence Interval } \\
\hline & Label & Estimate & SE & Lower & Upper & $\mathbf{Z}$ & $\mathbf{p}$ & $\%$ Mediation \\
\hline Indirect & $a \times b$ & 0.0622 & 0.00997 & 0.0426 & 0.0817 & 6.24 & $<.001$ & 79.5 \\
\hline Direct & $\mathrm{C}$ & 0.0161 & 0.01549 & -0.0143 & 0.0464 & 1.04 & 0.300 & 20.5 \\
\hline Total & $c+a \times b$ & 0.0782 & 0.01595 & 0.0470 & 0.1095 & 4.91 & $<.001$ & 100.0 \\
\hline
\end{tabular}

Table 6. Path Estimates for Transformational Leadership on Task Performance through OCB

\begin{tabular}{|c|c|c|c|c|c|c|c|c|c|}
\hline & & & \multicolumn{7}{|c|}{ 95\% Confidence Interval } \\
\hline & & & Label & Estimate & SE & Lower & Upper & $\mathbf{Z}$ & $\mathbf{p}$ \\
\hline LITRANS & $\rightarrow$ & OCB & $\mathrm{a}$ & 0.5335 & 0.0647 & 0.4066 & 0.6603 & 8.24 & $<.001$ \\
\hline $\mathrm{OCB}$ & $\rightarrow$ & PSAR & $\mathrm{b}$ & 0.1166 & 0.0122 & 0.0926 & 0.1405 & 9.54 & $<.001$ \\
\hline LITRANS & $\rightarrow$ & PSAR & $\mathrm{c}$ & 0.0161 & 0.0155 & -0.0143 & 0.0464 & 1.04 & 0.300 \\
\hline
\end{tabular}

Table 7. Mediation Estimates for Transformational Leadership on Contextual Performance through OCB

\begin{tabular}{|c|c|c|c|c|c|c|c|c|}
\hline \multirow[b]{2}{*}{ Effect } & \multicolumn{8}{|c|}{ 95\% Confidence Interval } \\
\hline & Label & Estimate & SE & Lower & Upper & $\mathbf{Z}$ & $\mathbf{p}$ & $\%$ Mediation \\
\hline Indirect & $a \times b$ & 0.0787 & 0.0108 & 0.05758 & 0.0997 & 7.32 & $<.001$ & 75.9 \\
\hline Direct & $\mathrm{c}$ & 0.0249 & 0.0118 & 0.00184 & 0.0480 & 2.12 & 0.034 & 24.1 \\
\hline Total & $\mathrm{c}+\mathrm{a} \times \mathrm{b}$ & 0.1036 & 0.0143 & 0.07550 & 0.1317 & 7.23 & $<.001$ & 100.0 \\
\hline
\end{tabular}

Table 8. Path Estimates for Transformational Leadership on Contextual Performance through OCB

\begin{tabular}{|c|c|c|c|c|c|c|c|c|c|}
\hline & & & \multicolumn{7}{|c|}{ 95\% Confidence Interval } \\
\hline & & & Label & Estimate & SE & Lower & Upper & $\mathbf{Z}$ & $\mathbf{P}$ \\
\hline LITRANS & $\rightarrow$ & OCB & $\mathrm{a}$ & 0.5335 & 0.06471 & 0.40664 & 0.6603 & 8.24 & $<.001$ \\
\hline $\mathrm{OCB}$ & $\rightarrow$ & PCON & $\mathrm{b}$ & 0.1474 & 0.00929 & 0.12923 & 0.1656 & 15.87 & $<.001$ \\
\hline LITRANS & $\rightarrow$ & PCON & $\mathrm{c}$ & 0.0249 & 0.01178 & 0.00184 & 0.0480 & 2.12 & 0.034 \\
\hline
\end{tabular}

H3: Correlation analysis was used to test if transformational leadership significantly correlated with employee performance. The results of the correlation analysis indicated positive and statistically significant associations of transformational leadership with both task performance, $r=.27, p<.01$, with an effect size $r^{2}=.07$, and contextual performance, $\mathrm{r}=.38, \mathrm{p}<.01$, with an effect size $\mathrm{r}^{2}=.14$.

H4: Correlation analysis was used to test if OCB was positively associated with performance. The results of the correlation indicated positive and statistically significant associations of OCB with both task performance, $r=.53, p$
$<.01$, with an effect size $\mathrm{r}^{2}=.28$, and with contextual performance, $r=.72, p<.01$, with an effect size $r^{2}=.52$.

\section{Mediation analyses}

H5: Firstly, mediation analysis was used to test if OCB mediated the relationship between transformational leadership and task performance, using MEDMOD module of JAMOVI (Jamovi project, 2018). The results of the mediation indicated that the indirect effect $\mathrm{M}=.06$ accounted for $79.5 \%$ of total effect, $95 \% \mathrm{CI}=.04, .08$.

Secondly, mediation analysis was used to test if OCB mediated the relationship between transformational 
leadership and contextual performance, using MEDMOD module of JAMOVI. The results of the mediation indicated that the indirect effect $\mathrm{M}=.08$ accounted for $75.9 \%$ of total effect, $95 \% \mathrm{CI}=.06, .10$.

\section{Discussion}

In this study we investigated the associations of transformational leadership with a set of organizational environment components such as organizational climate, organizational citizenship behavior and performance.

Transformational leadership proved to be strongly correlated with organizational climate; therefore, we can state that transformational leaders whose leadership is based on vision, personal recognition and support succeed in building and maintaining a satisfactory organizational climate for employees, in accordance with their needs and their desires.

Although there are many studies on the relationship between leadership styles and organizational climate, these issues have not been thoroughly investigated in Romania. However, our results are in line with the results of other studies. Haakonsson et al. (2008) conducted a survey of the inconsistencies between the organizational climate and the leadership style that led to negative performance. The questionnaires were completed by general managers and the researchers formulated their observations based on the answers provides by the former. The results showed that the incompatibility between the organizational climate and the leadership style generated serious problems in terms of business results and performance, which required changes in either the organizational climate or the leadership style. The study draws attention to the importance of constantly assessing the relationship of these variables so as to prevent problems at organizational level.

Sarros, Cooper, \& Santora (2008) conducted a study among 1,158 private Australian managers trying to identify the relationships of transformational leadership style, organizational culture, and innovation-oriented climate. The results showed that vision and support were the facets of transformational leadership style with the strongest links to organizational climate. At the same time, intellectual stimulation did not show significant correlations with the innovation-oriented organizational climate.

Similar results were also obtained by Antonakis and House (2002) or Mumford et al. (2002). Damanpour and Schneider (2006) argued that transformational leaders contributed to creating an innovation-based climate and facilitating changes at organizational level.

Transformational leadership was positively associated with OCB, which was consistent with other studies in the literature. Cho and Dansereau (2010) obtained similar results in a study on the relationship between transformational leadership, the perception of justice, and OCB. The authors used a sample of 159 employees, of whom 40 were managers from a multinational company in Korea. The results showed that transformational leadership was positively associated with $\mathrm{OCB}$, the relationship being mediated by the perception of justice.

Khalili (2017) examined the associations of transformational leadership, organizational citizenship behavior (OCB) of employees and the emotional intelligence (EI) of employees. Additionally, the study explored the moderating role of employees' EI on the relationship between transformational leadership and OCB. The study was conducted in 50 organizations in Iran, on a sample of 2,021 employees. The findings of this research showed that transformational leadership and employees' EI positively and significantly influenced employees' OCB. Additionally, the results revealed that employees' EI moderated the association between transformational leadership and employees' OCB.

Transformational leadership has proven to be positively correlated with performance. These results are similar to those found by Naeem and Khanzada (2018) in a study which explored the association between transformational leadership and employee performances, and also investigated the mediating role of job satisfaction in the health sector of Pakistan. Research data was collected from 152 respondents. The results showed that transformational leadership positively correlated with employee performance in the health sector of Pakistan.

Casimir, Waldman, Bartram, \& Yang (2006) also tested the effect of transactional and transformational leadership on the performance of subordinates by incorporating trust in leaders as intervening variable. The tests were conducted on two different companies within different cultures, i.e. Australia and China. The results in Australia showed that transformational leadership influenced the performance of subordinates and was mediated by the trust in leaders. On the other hand, the results in China showed that mediation of trust had no effect on the influence of transformational leadership on employees' performance.

The research conducted by Jung and Avolio (2000) tested the analysis of the effect of trust mediation and value congruence on transactional and transformational leadership. The results of that research revealed that transformational leadership had a very strong and positive influence on performance, mediated by trust and value congruence.

As far as the mediating role of organizational citizenship behavior, researchers noted that OCB mediated the relationship between leadership and performance, with higher effects on contextual performance than on task performance.

Similar results were obtained by Jiang, Zhao, \& Ni (2017) in a study on the mediating role of OCB in the relationship between transformational leadership and work performance. The authors noticed that OCB was responsible for more than $50 \%$ of the influence of leadership on performance, especially on relational performance.

On the other hand, a study conducted by Maharani, Troena, \& Noermijati (2013) on a group of employees at an Indonesian bank, found that transformational leadership did not influence OCB, that both transformational leadership and OCB had direct effects on performance and that OCB did not act as a mediating factor in the relationship between leadership and performance.

In our study, OCB has a significant mediation effect on performance. This leads to the conclusion that the leadership style determines the achievement of results to a certain extent, but the results are lesser in the absence of adequate citizenship behavior. Organizational citizenship behavior, although a complex construct that involves interacting with others, remains essentially a subjective variable, a personal way of manifesting in the organizational environment. If OCB brings about increased contextual performance and lower task performance, we can conclude that leadership style manages to partially model the behaviors of the members of an organization, but does not necessarily lead to effective performance. The 
human component has an important contribution to performance and does not always overlap with the broad objectives of the organization, the achievement of which is probably dependent on a variety of other factors that may be related to the type of work, the type of organization and the type of communication within the company.

\section{Limits and future research directions}

One limitation of this study consists in the choice of a new instrument to measure the organizational climate. Although it has been translated in accordance with all the rules and norms established in the field, the instrument is a relatively new one, with no rich history and sufficient references. Another limit of the study is that the crosssectional format does not allow some causal conclusions. Also, the instruments which were used, including those for performance, were self-reports, which may entail a high level of subjectivity of the provided answers.

The findings of this research can be considered the basis for developing training programs addressed not only to senior management employees, but also to employees in any positions, aiming to develop better communication methods and channels within organizations. At the same time, we aim to identify the ways in which to increase the quality and improve the organizational environment in general in order to stimulate performance, as this is a limitation of the Romanian organizational framework.

\section{Practical implications}

The present study offered a more accurate portrayal of the Romanian employees' perceptions regarding the leadership style, organizational climate, organizational citizenship behavior and work performance. These four aspects of the working environment are interdependent; they attract and reject one another according to the quality of their implementation and manifestation within organizations. This study may be the basis of a process of organizational diagnosis and program development so as to ameliorate the critical situations faced by some private Romanian companies.

Following the diagnostic analysis of the components of the organizational environment, specific sessions may be organized to improve the quality of these components in order to increase the employees' well-being, organizational citizenship behavior and the level of performance. In terms of leadership, companies may identify strengths and weaknesses in leadership, and alter them through specialized trainings. Most managers in Romania lead and manage their companies intuitively rather than based on scientifically proven principles. A more scholastic approach to leadership is likely to bring benefits both at individual level - to both managers and employees, as well as globally, driving consistent results in the organization.

\section{References}

Ackfeldt, A. L., \& Leonard, V. C. (2005). A study of organizational citizenship behaviors in a retail setting. Journal of Business Research, 58, 151-159.

Andrew, J. W., Rebecca, J. R., Shawn, A, S. (2011). Fitting Engagement Into a Nomological Network. The Relationship of Engagement to Leadership and Personality. Journal of Leadership \& Organizational Studies, 18(4), 522-537.

Antonakis, J., House, R. J. (2002). The full range leadership theory: The way forward. În B. J. Avolio și F. J. Yammarino (Eds.), Transformational and charismatic leadership: The road ahead (pp. 3-34). Oxford, UK: Elsevier.

Asgari, A., Daud, S., Aminah, A., Abu, S. B. (2008). The relationship between transformational leadership behaviors, organizational justice, Leader-Member Exchange, Perceived Organizational Support, Trust in Management and organizational Citizenship Behaviors. European Journal of Scientific Research, 23(2), 227-242.

Avolio, B. J., \& Bass, B. M. (1988). Transformational leadership, charisma, and beyond. In J. G.Hunt, B. R. Baliga, H. P. Dachler, \& C. A. Schriesheim (Eds.), Emerging leadership vitas (pp. 29-49). Lexington, MA: Lexington Books.

Avolio, B. J., Yammarino, F. J. (1990). Operationalizing charismatic leadership using a levels-of-analysis framework. The Leadership Quarterly, 1(3), 193-208.

Bakker, A. B., Heuven, E. (2006). Emotional Dissonance, Burnout, and In-Role Performance Among Nurses and Police Officers. International Journal of Stress Management, 13(4), 423-440.

Bartram, D., Hambleton, R. K. (Eds.) (2006). Computer-based testing and the Internet. Chichester, UK: Wiley and Sons.

Bass, B. M. (1985). Leadership and performance beyond expectations. New York: Free Press.

Bass, B. M. (1998). Transformational leadership: Industrial, military, and educational impact. Mahwah, NJ: Erlbaum.

Bass, B. M. (1999). Two decades of research and development in transformational leadership. European Journal of Work and Organizational Psychology, 8(1), 9-32.

Bass, B. M., \& Avolio, B. J. (1994). Improving organizational effectiveness through transformational leadership. Thousand Oaks, CA: Sage.

Bass, B. M. (1990). From transactional to transformational leadership: Learning to share the vision. Organizational Dynamics, 8, 19-31.

Bennis, W., Nanus, B. (1985). Leaders. Strategies for Taking Charge. Available online at http://coachjacksonspages. com/44.pdf.

Bergeron, D. M. (2007). The potential paradox of organizational citizenship behavior: Good citizens at what cost?. Academy of Management Review, 32(4), 10781095.

Boerner, S., Eisenbeiss, S. A., Griesser, E. (2007). Follower Behavior and Organizational Performance: The Impact of Transformational Leaders. Journal of Leadership and Organizational Studies, 13(3), 15-26.

Bono, J. E., Judge, T. A. (2003). Self-concordance at work: Toward understanding the motivational effects of transformational leaders. Academy of Management Journal, 46, 554-571.

Borman, W. C., Motowidlo, S. J. (1993). Expanding the criterion domain to include elements of contextual performance. În N. Schmitt, W. C. Borman şi colab. (Eds.), Personnel selection in organizations, pag. 71-98. San Francisco: Jossey-Bass.

Burns, J. M. (1978). Leadership. New York, NY: Harper \& Row.

Calahane, H., Sites, E. W. (2008). The climate of public child welfare employee retention. Child Welfare, 87(1), 91-114.

Carr, J. Z., Schmidt, A. M., Ford, J. K., DeShon, R. P. (2003). Climate perceptions matter: A meta-analytic path analysis relating molar climate, cognitive and affective states, and individual level work outcomes. Journal of Applied Psychology, 88, 605-619.

Casimir, G., Waldman, D., Bartram, T. and Yang, S. (2006). Trust and relationship between leadership and follower performance: Opening Black box in Australia and China. Journal of Leadership and Organizational Studies, 12(3), 156-190. 
Chiang, F. C., Tsung, S. H. (2012). The impacts of perceived organizational support and psychological empowerment on the job performance: the mediating effects of organizational citizenship behavior. International Journal of Hospitality Management, 31, 180-190.

Cho, J., Dansereau, F. (2010). Are transformational leaders fair? A multi-level study of transformational leadership, justice perceptions, and organizational citizenship behaviors, The Leadership Quarterly, 21, 409-421.

Colquitt, J., Noe, R., Jackson, C. 2002. Justice in teams: Antecedents and consequences of procedural justice climate. Personnel Psychology, 55, 83-109.

Corral, S., Pereña, J. (2010). Cuestionario de clima laboral. Manual [Work Climate Questionnaire. Manual] (2a ed.). Madrid: TEA Ediciones.

Cropanzano, R., Mitchell, M. S. (2005). Social exchange theory: An interdisciplinary review. Journal of Management, 31, 874-900.

Damanpour, F., Schneider, M. (2006). Phases of the adoption of innovation in organizations: Effects of environment, organization and top managers. British Journal of Management, $\quad$ 17, 215-236.

Demerouti, E., Taris, T. W., Bakker, A. B. (2007). Need for recovery, home-work interference and performance: Is lack of concentration the link? Journal of Vocational Behavior, 71, 204-220.

Detert, J. R., Burris, E. R. (2007). Leadership behavior and employee voice: Is the door really open? Academy of Management Journal, 50, 869-884.

Downing, S. M., Haladyna, T. M. (2006). Handbook of test development. Mahwah, NJ: Erlbaum.

Dvir, Eden, Avolio, \& Shamir (2002). Impact of transformational leadership on follower development and performance: A field experiment. Academy of Management Journal, 45(4), 735-744.

Ehrhart, M. 2004. Leadership and procedural justice climate as antecedents of unit-level organizational citizenship behavior. Personnel Psychology, 57, 61-94.

Eisenbeiss, S. A., Boemer, S. (2013). A double-edged sword: Transformstional leadership and individual creativity. British Journal of Management, 24, 54-68.

Ekowati, V. M., Troena, E. A., \& Noermijati, N. (2013). Organizational Citizenship Behavior Role in Mediating the Effect of Transformational Leadership, Job Satisfaction on Employee Performance: Studies in PT Bank Syariah Mandiri Malang East Java. International Journal of Business and Management, 8(17), 1.

Ekvall, G., Tangeberg-Andersson, Y. (1986). Working Climate and Creativity: A Study of an Innovative Newspaper Office. Journal of Creative Behavior, 20(3), 215-225.

Evans, K., Hodkinson, P., Rainbird, H., Unwin, L. (2006). Improving Workplace Learning. London, Routledge.

Farag, A. A., Tullai-McGuinness, S., Anthony, M. K. (2009). Nurses' perception of their manager's leadership style and unit climate: are there generational differences? Journal of Nursing Management, 17, 26-34.

Gardner, W. L., \& Avolio, B. J. (1998). The charismatic relationship: A dramaturgical perspective. Academy of Management Review, 23, 32-58.

Gil, F., Rico, R., Alcover, C. M., Barrasa, A. (2005). Changeoriented leadership, satisfaction and performance in work groups. Effects of team climate and group potency. Journal of Managerial Psychology, 20(3/4), 312-328.

Goldberg, C., Riordan, C. M., Zhang, L. (2008). Employees' Perceptions of Their Leaders. Is Being Similar Always Better? Group and Organizational Management, 33(3), 330-355.

Goodman, S. A., Svyantek, D. J. (1999). Person-organization fit and contextual performance: Do shared values matter. Journal of Vocational Behavior, 55(2), 254-275.
Goussak, G. W., Webber, J. K. (2011). Employee perception of leadership styles by Las Vegas casino-gaming managers. International Journal of Management and Marketing Research, 4(2), 85-98.

Haakonsson, D. D, Burton, R. M., Obel, B., Lauridsen, J. (2008). How failure to align organizational climate and leadership style affects performance. Management Decision, 46(3), 406-432.

Hannah, S. T., Luthans, F. (2008). A cognitive affective processing explanation of positive leadership: Toward theoretical understanding of the role of psychological capital. În: R. H. Humphrey, Ed., Affect and emotion: new directions in management theory and research of research in management, vol. 7. Charlotte, NC: Information Age Publishing.

Herold, D. M., Fedor, D. B., Caldwell, S., Liu, Y. (2008). The effect of transformational and change leadership on employees commitment to a change: A multilevel study. Journal of Applied Psychology, 93, 346-357.

Hiller, N. J., DeChurch, L. A., Murase, T., Doty, D. (2011). Searching for outcomes of leadership: A 25-year review. Journal of Management, 37, 1137-1177.

James, L. R., Choi, C. C., Ko, C. E., McNeil, P. K., Minton, M. K., Wright, M. A., Kim, K. (2008). Organizational and psychological climate: A review of theory and research. European Journal of Work and Organizational Psychology, 17(1), 5-32.

Jamovi project (2018). jamovi (Version 0.9) [Computer Software]. Retrieved from https://www.jamovi.org.

Jiang, W., Zhao, X., Ni, J. (2017). The Impact of Transformational Leadership on Employee Sustainable Performance: The Mediating Role of Organizational Citizenship Behavior. Sustainability, 9, 1-17.

Jones, A.P., James, L.R. (1979). Psychological climate: Dimensions and relationships of individual and agregated work environment perceptions. Organizational Behaviour and Human Performance, 23, 201-250

Jung, D., Avolio, B. (2000). Opening the black box: an experimental investigation of the mediating effects of trust and value congruence on transformational and transactional leadership. Journal of Organizational Behavior, 21(8), 949-964.

Khalili, A. (2017). Transformational leadership and organizational citizenship behavior: The moderating role of emotional intelligence. Leadership \& Organization Development Journal, 38(7), 1004-1015.

Khokhar, A. M., Zia-ur-Rehman, M. (2017). Linking Ethical Leadership to Employees' Performance: Mediating Role of Organizational Citizenship Behavior and Counterproductive Work Behavior. Pakistan Journal of Commerce and Social Sciences, 11(1), 321-350.

Koene, B. A. S., Vogelaar, A. L. W., \& Soeters, J. L. (2002). Leadership effects on organizational climate and financial performance: Local leadership effect in chain organizations. Leadership Quarterly, 13, 193-215.

Koys, D. J., DeCotiis, T. A. (1991). Inductive Measures of Psychological Climate. Human Relations, 44(3), 265-285.

Krishnan, V. R. (2005). Transformational leadership and outcomes: Role of relationship duration. Leadership \& Organization Journal, 26(5/6), 442-457.

Kuenzi, M., \& Schminke, M. (2009). Assembling fragments into a lens: A review, critique, and proposed research agenda for the organizational work climate literature. Journal of Management, 35, 634-717.

Lee, K., Allen, N. (2002). Organizational citizenship behavior and workplace deviance: the role of affect and cognitions. Journal of Applied Psychology, 87, 131-142.

Levay, C. (2010). Charismatic leadership in resistance to change. The Leadership Quarterly, 21, 127-143.

Lian, K. L., Tui, L. G. (2012). Leadership Styles and Organizational Citizenship Behavior: The Mediating 
Effect of Subordinates' Competence and Downward Influence Tactics. Journal of Applied Business and Economics, 13(2), 59-96.

Liu, X, Batt, R. (2010). How supervisors influence performance: A multilevel study of coaching and group management in technology-mediated services. Personnel Psychology, 63, 265-298.

Luthans, F. (2011). Organizational Behavior. An EvidenceBased Approach (editia a 12-a). New York: McGraw-Hill International Edition.

Mackenzie, S. B., Podsakoff, P. M., Rich, G. A. (2001). Transformational and transactional leadership and salesperson performance. Journal of Academy of Marketing Science, 29, 396- 410.

Maharani, V. M., Troena, E. A., \& Noermijati, N. (2013). Organizational Citizenship Behavior Role in Mediating the Effect of Transformational Leadership, Job Satisfaction on Employee Performance: Studies in PT Bank Syariah Mandiri Malang East Java. International Journal of Business and Management, 8(17).

Manas-Rodríguez, M. A., Alcaraz-Pardo, L., Pecino-Medinaa, V., Limbert, C. (2016). Validation of the Spanish version of Soane's ISA Engagement Scale. Journal of Work and Organizational Psychology, 32, 87-93.

McKay, P. F., Avery, D. R., Morris, M. A. 2008. Mean racialethnic differences in employee sales performance: The moderating role of diversity climate. Personnel Psychology, 61, 349-374.

Moss, S. A., Dowling, N., Callanan, J. (2009). Towards an integrated model of leadership and self regulation. Leadership Quarterly, 20, 162-176.

Mumford, M. D., Scott, S. M., Gaddis, B., Strange, J. M. (2002). Leading creative people: Orchestrating expertise and relationships. Leadership Quarterly, 13, 705-750.

Muniz, J., Pena-Suarez, E., de la Roca, Y., Fonseca-Pedrero, E., Cabal, A. L., Garcia-Cueto, E. (2014). Organizational climate in Spanish public health services: Administration and services staff. International Journal of Clinical and Health Psychology, 14, 102-110.

Naeem, S., Khanzada, B. (2018). Role of Transformational Leadership in Employee's Performance with Mediating Role of Job Satisfaction in Health Sector of Pakistan. Journal of Health Education Research \& Development, 6(1), 1-6. doi: 10.4172/2380-5439.1000245.

Oguz, E. (2010). The relationship between the leadership styles of the school administrators and the organizational citizenship behaviours of teachers. Procedia Social and Behavioral Sciences, 9, 1188-1193.

Organ, D. W. (1988). Organizational citizenship behavior: The good soldier syndrome. USA: D.C. Heath and Company.

Organ, D. W., Podsakoff, P. M., MacKenzie, S. B. (2006). Organizational citizenship behavior: Its nature, antecedents, and consequences. USA: Sage Publications, Inc.

Ostroff, C. (1993). The effects of climate and personal infl uences on individual behavior and attitudes in organizations. Organizational Behavior and Human Decision Processes, 56, 56-90.

Patterson, M., Warr, P., West, M. (2004). Organizational climate and company productivity: The role of employee affect and employee level. Journal of Occupational and Organizational Psycholog, 77(2), 193-216.

Pena-Suarez, E., Muniz, J., Campillo-Alvarez, A., FonsecaPedrero, E., Garcia-Cueto, E. (2013). Assessing organizational climate: Psychometric properties of the CLIOR Scale. Psicothema, 25(1),137-144.

Piccolo, R., Colquitt, J. (2006). Transformational Leadership and Job behavior: The mediating role of job characteristic. Academy of Managerial Journal, 49(2), 327-340.
Podsakoff, N. P., Whiting, S. W., Podsakoff, P. M., Blume, B. D. (2009). Individual- and organizational-level consequences of organizational citizenship behaviors: A metaanalysis. Journal of Applied Psychology, 94(1), 122141.

Podsakoff, P. M., MacKenzie, S. B., Paine, J. B., Bachrach, D. G. (2000). Organizational citizenship behaviors: a critical review of the theoretical and empirical literature and suggestions for future research. Journal of Management, 26(3), 513-563.

Rafferty, A. E., Griffin, M. A. (2004). Dimensions of transformational leadership: Conceptual and empirical extensions. The Leadership Quarterly, 15(3), 329-354.

Rafferty, A. E., Restubog, S. L. D. (2010). The Impact of Change Process and Context on Change Reactions and Turnover During a Merger. Journal of Management, 36(5), 1309-1338.

Sarros, J. C., Cooper, B. K., Santora, J. C. (2008). Building a climate for innovation through transformational leadership and organizational culture. Journal of Leadership \& Organizational Studies, 15(2), 145-158.

Schlechter, A. F., Engelbrecht, A. S. (2006). The relationship between transformational leadership, meaning and organizational citizenship behavior. Management Dynamics, 15(4), 2-16.

Schneider, B., Reichers, A. E. (1983). On the etiology of climates. Personnel Psychology, 36, 19-39.

Schneider, B., Ehrhart, M. G., Macey, W. H. (2013). Organizational climate and culture. Annual Review of Psychology, 64, 361-388.

Smith, C. A., Organ, D. W., Near, J. P. (1983). Organizational citizenship behavior: Its nature and antecedents. Journal of Applied Psychology, 68, 653- 663.

Strauss, K., Griffin, M. A., Rafferty, A. (2009). Proactivity directed toward the team and organization: the role of leadership, commitment and role-breadth self-efficacy. British Journal of Management, 20(3), 279-291.

Stringer, R. (2002). Leadership and organizational climate. New York: Prentice Hall.

Sun, L-Y., Aryee, S., Law, K. S. (2007). Citizenship behavior and organizational performance: A relational perspective. Academy of Management Journal, 50(3), 558-577.

Tichy, N. M., Devanna, M. A. (1986). The transformational leader. New York: Wiley.

Turnipseed, D. L., Rassuli, A. (2005). Performance Perceptions of Organizational Citizenship Behaviours at Work: a Bi-Level Study among Managers and Employees. British Journal of Management, 16(3), 231244.

Van Scotter, J. R., Motowidlo, S. J., Cross, T. C. (2000). Effects of task performance and contextual performance on systemic rewards. Journal of Applied Psychology, 85(4), 526-535.

Vera, D., Crossan, M. (2004). Strategic leadership and organizational learning. Academy of Management Review, $29,222-240$.

Wang, G., Oh, I-S., Courtright, S. H., Colbert, A. E. (2011) Transformational Leadership and Performance Across Criteria and Levels: A Meta-Analytic Review of 25 Years of Research. Group \& Organization Management, 36(2), 223-270.

Wang, H., Law, K. S., Hackett, R. D., Wang, D. și Chen, Z. X. (2005). Leader-member exchange as a mediator of the relationship between transformational leadership and followers' performance and organizational citizenship behavior. Academy of Management Journal, 48, 420-432.

Wang, H., Tsui, A. S., Xin, K. R. (2011). CEO leadership behaviors, organizational performance, and employees' attitudes. The Leadership Quarterly, 22, 92-105. 
Werner, J. M., 2000. Implications of OCB and contextual performance for human resource management. Human Resource Management Review 10(1), 3-24.

Whitford, T., Moss, S. A. (2009). Transformational leadership in distributed work groups: The moderating role of follower regulatory focus on goal orientation. Communication Research, 36(6), 810-837.

Yukl, G., Howell, J. M. (1999). Organizational and contextual influences on the emergence and effectiveness of charismatic leadership. Leadership Quarterly, 10, 257283 .

Zohar, D., Tenne-Gazit, O. (2008). Transformational leadership and group interaction as climate antecedents: A social network analysis. Journal of Applied Psychology, 93, 744-757. 